\title{
Sustentabilidade e Aplicabilidade Organizacional sob a Ótica Acadêmica
}

\begin{tabular}{ll}
\hline & Instituto Federal de Educação, Ciência e Tecnolo- \\
Marjana Eloisa Henzel & gia Farroupilha - IFFar, Campus Alegrete. \\
& RS-377 - Km 27 - Passo Novo - CEP 97555-000 - \\
& Alegrete/RS, Brasil. \\
& E-mail: marjana.henzel@iffarroupilha.edu.br \\
\hline \multirow{3}{*}{ Jessica Martins } & Instituto Federal de Educação, Ciência e Tecnologia \\
& Farroupilha - IFFar, Campus Santa Rosa. \\
Cheila Carla Szast & Rua Uruguai, 1675 - Bairro Central - CEP: 98900- \\
& 000, Santa Rosa, RS, Brasil. \\
& E-mails: \\
Laise Polla & jessicamschubert@hotmail.com, cheila- \\
& szast@hotmail.com, laise.pollaa@hotmail.com \\
\hline
\end{tabular}

Recebido em: 11 ago. 2016. Aceito: 03 fev. 2017.

DOI: http://dx.doi.org/10.21674/2448-0479.31.150-170

\section{Resumo}

A Gestão Ambiental é temática trivial da contemporaneidade, pauta de inúmeras discussões, grupos de estudos e também disciplina curricular. Sob esta ótica e sabendo da relevância deste tema é que se apresenta este artigo que tem como objetivo abordar a temática e suas contribuições para o meio acadêmico. O universo contemplado é o Curso Superior de Bacharelado em Administração do IFFarroupilha Campus Santa Rosa - RS com a perspectiva de aproximação entre conceitos e teorias estudadas. Elaborou-se um exercício para o desenvolvimento da tomada de decisões que visam à 
sustentabilidade, perenidade e competitividade dos negócios organizacionais. O estudo proporcionou uma análise do cenário atual de uma determinada organização, a partir desse contexto, foram criadas metodologias para a implementação de uma nova ferramenta de gestão sustentável, foco de estudo da disciplina do semestre letivo do curso; Gestão Ambiental. Dessa forma, a atividade contribuiu para o desenvolvimento de habilidades e competências do profissional em Administração, que tem como essência a formação teórica e prática, voltada à viabilidade e sustentabilidade das organizações. Por fim, entende-se que a sala de aula deve, sim, proporcionar exercícios que conduzam os acadêmicos a situações próximas da realidade, para que, de maneira efetiva, eles estejam capacitados para as adversidades inerentes ao mundo do trabalho.

Palavras-chave: Prática. Ensino. Administração. Sustentabilidade.

\section{Abstract \\ Sustainability and organizational applicability from academic perspective}

Environmental management is trivial theme of contemporary times, the agenda of numerous discussions, study groups and curricular discipline. From this perspective and knowing the importance of this matter is that it presents this article aims to address the issue and their contributions to academia. The universe is awarded the BacheIor Degree in Administration IFFarroupilha Campus Santa Rosa - RS with the prospect of rapprochement between concepts and theories studied. It developed an exercise for the development of decisionmaking aimed at sustainability, sustainability and competitiveness of 
organizational business. The study provided an analysis of the current scenario of an organization, from that context, methodologies were created for the implementation of a new sustainable management tool, focus of study the course of the semester of the course; Environmental management. Thus, the activity has contributed to the development of skills and competencies of professional Administration, whose essence the theoretical and practical training, focused on the viability and sustainability of organizations. Finally, it is understood that the classroom should, yes, provide exercises leading academics to close to reality situations, so that, effectively, they are empowered to adversities inherent in the working world.

Keywords: Practice. Education. Management. Sustainability.

\section{Introdução}

O Curso Superior de Bacharelado em Administração do Instituto Federal Farroupilha - Campus Santa Rosa/RS, tem como objetivo constituir profissionais com sólida formação teórica e prática, voltados à viabilidade e sustentabilidade das organizações, a partir do desenvolvimento das habilidades e competências de gestão e liderança que constam no Projeto Pedagógico do Curso Superior de Bacharelado em Administração (INSTITUTO FEDERAL FARROUPILHA, 2014). Alinhadas a isso, ao Plano de Desenvolvimento Institucional - PDI, e comprometidas com a missão Institucional de promover a educação profissional, científica e tecnológica, pública, por meio do ensino, pesquisa e extensão, com foco na formação integral do cidadão e no desenvolvimento sustentável, é que as atividades de ensino do curso estão voltadas à interação teórica e prática, sob 
a análise dos cenários organizacionais (INSTITUTO FEDERAL FARROUPILHA, 2014).

O curso possibilita a formação de profissionais para competências e habilidades, conforme as Diretrizes Curriculares Nacionais do Bacharelado em Administração (CONSELHO NACIONAL DE EDUCAÇÃO, 2005), reconhecendo e definindo problemas, pensando estrategicamente, generalizando conhecimentos e exercendo, em diferentes graus de complexidade, o processo da tomada de decisão. Prima pelo significado e aprofundamento de conhecimentos acadêmicos, mediante a contextualização e a interdisciplinaridade, estimulando o raciocínio e a capacidade de aprender de todos os envolvidos no processo de ensino e de aprendizagem.

No terceiro semestre, é possibilitado ao futuro profissional trabalhar conteúdos nas disciplinas de Marketing I, Estatística, Direito do Consumidor, Comportamento Organizacional, Gestão Ambiental e Organização de Sistemas e Métodos (OSM). Nesta última disciplina, de OSM, desenvolveu-se um trabalho que buscou conhecimento e aplicações sobre organização, sistemas e métodos organizacionais, suas práticas e seus fundamentos teóricos, articulando conhecimento sobre as ferramentas específicas, para subsidiar tomadas de decisões que visem à sustentabilidade, à perenidade e à competitividade no negócio.

Em todos os demais semestres do curso Superior de Administração, tem-se a organização curricular formada por diferentes disciplinas, que estão divididas em três núcleos (comum, específico e complementar) as quais possibilitam ao acadêmico conhecimentos de conteúdos básicos da área, de formação profissional e suas tecnologias e de atualização constante, para a efetiva conclusão do curso, oferecido na modalidade presencial. No total, são ofertadas 
35 vagas/ano, com regime letivo semestral e com tempo de duração de 8 semestres (4 anos).

Dessa forma, este estudo vem ao encontro das demandas propostas por esses objetivos e está direcionado ao exercício de diagnóstico, análise e aplicabilidade de ferramentas destinadas à elaboração de métodos para a melhoria organizacional, sob o olhar do desenvolvimento sustentável e da temática ambiental.

\section{Fundamentação Teórica}

As atividades de ensino que abordam os cenários organizacionais passam pela compreensão do texto teórico estudado, analisado e discutido em sala de aula. Dessa forma, a disciplina de OSM, ofertada no terceiro semestre do curso, apresenta-se, conforme Cruz (2002), como sendo o estudo das organizações por meio da análise de cada uma das atividades, a fim de criar procedimentos que venham a interligá-las de forma sistêmica.

Sob a ótica de Rocha (1998), OSM é a função mista de Organização e Planejamento, desenvolvida na construção da estrutura de recursos e de operações de uma instituição, assim como na determinação de seus planos, principalmente na definição dos procedimentos, das rotinas e dos métodos. No ementário curricular dessa disciplina, tem-se ainda a temática sobre as Novas Estruturas Organizacionais, em que os autores Magro e Teló (2011) discutem o motivo das mudanças nas estruturas organizacionais, como fusão e incorporação, que ocorrem para a ampliação de mercado.

Já a disciplina de Gestão Ambiental, contemplada no mesmo semestre letivo, tem o espelhamento dos autores Höfler et al. (2014), que apresentam, em sua obra, inúmeros cases de empresas que aplicaram e utilizaram métodos e ferramentas ambientais para a correlação empresa e gestão. A gestão socioambiental deve visar 
ao equilíbrio entre os elementos, a política e a relação com o meio ambiente, entendendo-se esses itens, respectivamente, como os aspectos, as decisões e os impactos ambientais (FERREIRA et al., 2008).

Devido aos problemas ocasionados ao meio ambiente, a sociedade passou a cobrar mais competência e ética das organizações, para minimizar danos à natureza, que consequentemente afetavam a coletividade (NETO et al., 2011). Após estudos feitos no histórico ambiental, as empresas passaram a ter uma preocupação com essa questão. Através da relevante importância dada à gestão ambiental, as empresas constataram que demonstrar qualidade ambiental é um item considerado importante por seus clientes, já que esses são as pessoas mais informadas e motivadas para o assunto.

\section{Metodologia}

A realidade das organizações não se apresenta de forma fragmentada, mas de forma complexa e diversa. Sob esta ótica o Curso de Administração em seu PPC (INSTITUTO FEDERAL FARROUPILHA, 2014) contempla essa unicidade tendo seu desenvolvimento pautado na interdisciplinaridade.

Este estudo busca diagnosticar e identificar, através de critérios descritivos, a estrutura organizacional de uma empresa do ramo alimentício localizada na região noroeste do Rio Grande do Sul, a elaboração de um departamento de Gestão Ambiental, a criação de um setor terceirizado e a implantação da norma ambiental ISO 14001:2004.

Para se chegar a essas informações, utilizou-se como base o estudo de caso direcionado à aplicabilidade organizacional; para o 
tratamento das informações, fez-se uso da técnica de análise de conteúdo, sendo abordada uma prestabilidade crítica do assunto.

Também foi utilizada a pesquisa bibliográfica, uma vez que ela serve para arrematar categoricamente os significados acadêmicos, para a complementação do estudo e, imprescindivelmente, para a fundamentação teórica que este contempla.

\section{Resultados e Discussão}

O estudo proporcionou análises quanto ao referencial teórico apresentado, aliado à interdisciplinaridade do curso. Dessa forma, aprofundou os conhecimentos de OSM, através de uma visão organizacional e, nos conhecimentos de Gestão Ambiental, para uma visão social e estratégica da organização. Para Teixeira (2004, p.64), "o significado de interdisciplinaridade evidencia um cruzamento de saberes disciplinares no campo científico e um esforço organizado de coordenação, cooperação e comunicação menos assimétrica".

\section{A Utilização da Ferramenta 5w2h}

Para Höfler, Wagner e Juchen (2014), a ferramenta 5W2H é uma das mais fáceis de ser implementada e, ao mesmo tempo, é muito útil para os gestores, pois elimina possíveis dúvidas que possam surgir sobre os processos e suas atividades. A ausência de dúvidas traz grandes melhorias para as atividades planejadas de checklist, pois qualquer entendimento errado da tarefa que está sendo executada pode acabar trazendo prejuízos para a empresa.

Para Vergara (2006), o 5W2H é um plano de ação que serve para mapeamento e padronização de processos, além de estabele- 
cer procedimentos associadores e indicadores. Segundo Santos, Guimarães e Brito (2013), é uma ferramenta basicamente gerencial e busca a compreensão da definição de responsabilidade, métodos, prazos, objetivos e os recursos associados. Logo, realizando o estudo através da ótica do $5 \mathrm{~W} 2 \mathrm{H}$, pode-se observar alguns aspectos, conforme segue:

a) Why - O porquê; motivo que será considerado para a elaboração e a implementação do projeto; para administrar e controlar os processos de Gestão Ambiental; para diminuir erros; para ter um melhor reconhecimento no mercado;

Segundo Oliveira (2014), essa ferramenta é a justificativa dos objetivos pelo qual o sistema de gestão ambiental deve ser implantado na organização. Além de identificar o motivo da realização deste programa, a ferramenta permite uma explicação mais clara e sem prolongamentos sobre o plano interno de sustentabilidade previsto na empresa.

É preciso ter em vista que o projeto deve ser inserido de forma concisa, para que, além de todos os benefícios de conscientização na redução de desperdícios, a empresa possa desfrutar também de uma melhor certificação de qualidade para benefícios da sua empresa.

b) Who - Quem serão os responsáveis pela elaboração do projeto? Refere-se aos autores da elaboração do projeto e dos processos nele envolvido. Os Coordenadores de Gestão Ambiental;

Nas palavras de Dias (2011, p. 111): 
atualmente, muitos valores culturais relacionados com o meio ambiente, a infraestrutura e os conhecimentos técnicos são trazidos pelas empresas transnacionais. Desta forma, a difusão de uma cultura ambiental, embutida na cultura organizacional, se dá através da troca de lideranças, técnicos e outros profissionais que incorporam novos hábitos e costumes e os repassam às demais empresas.

Nesse plano de ação, as fases da ISO 14001:2004 serão executadas pelos mesmos responsáveis que eram encarregados da qualificação da Norma ISO 9001:2000, sem deslocar os demais trabalhadores de suas funções. Na fase da manutenção, todos eles serão envolvidos, contando com treinamentos, regras e um novo padrão de conduta, para que os coordenadores de gestão ambiental possam implantar a Norma ISO 14001 dentro na empresa.

c) When - Quando a ação deve ser realizada? É um planejamento temporal, onde avaliam-se as condições que envolvem a elaboração do projeto. Prazo de cinco meses: de maio a outubro;

Quanto maior a importância do significado "Meio Ambiente" dentro de uma empresa, mais forte será a cultura ambiental nela implantada; e quanto maior for o valor dessa cultura, mais cedo o interesse pela implantação de sistemas ambientais será despertado. Dessa forma, a cultura organizacional terá uma orientação ambiental mais enfatizada.

Traça-se um cronograma, detalhando-se os prazos para o cumprimento das tarefas, com a equipe já definida, com suas responsabilidades e tarefas, cumprindo os períodos predefinidos no planejamento; nesse caso, com prazo de cinco meses. Nessa ação, todo o controle e foco do processo é de suma importância, uma vez 
que o descumprimento do tempo da ação pode comprometer todo o projeto. Assim, a equipe será eficiente na implantação da ISO 14001.

d) What - O que deve ser feito? O projeto é sobre o quê? Refere-se ao projeto em si, mais especificamente ao objeto do projeto. Implementação da norma ISO 14001;

De acordo com Albuquerque (2008), a norma internacional ABNT NBR ISO 14001 dá diretrizes para a implementação de um sistema de gestão ambiental. É uma forma eficaz de planejar, organizar e praticar ações ambientais, podendo integrar-se a outros elementos da gestão empresarial. Para a maior parte das empresas, obter a certificação da ISO 14001 é suficiente para demonstrar o comprometimento com práticas sustentáveis e mesmo exportar para o exterior.

Uma vez implementado o sistema de gestão ambiental através da ISO 14001, a organização consegue perseguir e atingir diversos objetivos, como aperfeiçoamento contínuo de seu desempenho ambiental, diminuição do uso de matéria-prima e produtividade.

Porém, Viterbo (1998) diz que a atividade só deve ser feita após a determinação inicial dos aspectos ambientais, como no caso da análise preparatória, pois as leis, regulamentos e códigos devem estar associadas aos aspectos.

A adoção de Sistemas de Gestão Ambiental nas empresas deve vir acompanhada de mudanças culturais; as pessoas devem, por si só, estar mais comprometidas com a nova perspectiva da empresa. Nesse sentido, alguns hábitos e costumes enraizados que são resistentes no ambiente externo das empresas devem ser com- 
batidos, e outros, concordantes, devem ser assimilados pelo conjunto da organização (DIAS, 2011).

e) Where - Onde a ação será executada? Refere-se ao local em que será realizado o projeto. Neste caso, em uma empresa do setor de alimentos da região noroeste do RS;

A empresa é dividida em setores responsáveis por determinadas áreas. Surge a oportunidade e, ao mesmo tempo, a necessidade de se implantar um sistema de gestão ambiental, que pode trazer diversas conceituações empresariais no controle e na emissão de poluentes ou no consumo de recursos naturais. Existe a preocupação com fiscalizações das atividades praticadas na empresa, que, se trouxerem resultados positivos, poderão receber renomadas certificações de qualidade, as quais terão grande importância para o setor alimentício e serão capazes de chamar a atenção futura de consumidores. Em razão disso, a norma ISO 14001 será implantada no setor de alimentos da empresa.

f) How many - Como será feito esse projeto? Quais processos serão realizados? Trata-se dos meios e métodos definidos para concretizar o processo; o aproveitamento dos serviços dos colaboradores que efetuam a qualidade da ISO 9001 na empresa, juntamente com os colaboradores novos, atuantes na Gestão Ambiental, para implementar a ISO 14001.

Esse plano de ação estabelece a maneira mais racional e acessível (em relação às despesas) de efetuar as tarefas. Viterbo Junior (1998) diz, que "isso deve ser feito formalmente, pois a Norma 14001 pede um procedimento formal (padrão documentado) 
estabelecendo como a organização identifica os aspectos ambientais de suas atividades, produtos ou serviços. Este procedimento terá importância fundamental no desenvolvimento das demais atividades". No entanto, isso deverá ser feito a partir de planejamentos voltados à conformação e à inserção desse sistema de gestão ambiental.

Nesse sentido, a empresa será a responsável em trabalhar organizadamente na identificação dos procedimentos ambientais necessários para a implantação da Norma ISO 14001, atuando juntamente com os colaboradores que já prestavam serviços para a gestão ambiental da empresa, com os serviços de qualidade da Norma ISO 9001, a fim de evitar custos com a contratação de novos responsáveis.

g) How much - Quanto custará a elaboração do projeto? Refere-se ao valor anteriormente definido, que é determinado para a elaboração total do projeto. Valor definido: aproximadamente $R \$ 45.000,00$;

Segundo Graça e Godoy (2012), essa parte da ferramenta se refere ao custo da realização, da mudança e da operação atual. Assim, pode-se, a partir disso, analisar de forma mais planejada 0 custo/benefício com a implantação de um novo setor dentro da organização.

\section{Construção do Organograma e Fluxograma}

O organograma a seguir foi elaborado a partir do desafio da criação de uma unidade de produção terceirizada, de tal maneira que deve aderir a algumas normas de gestão para que se enquadre 
na produção de qualidade da empresa. Um desses critérios é a adesão à Norma de Gestão Ambiental ISO 14001:2004, logo o organograma define os departamentos responsáveis pelo controle de Gestão Ambiental da terceirizada, tanto em seus processos produtivos quanto operacionais, conforme apresentado na Figura 1.

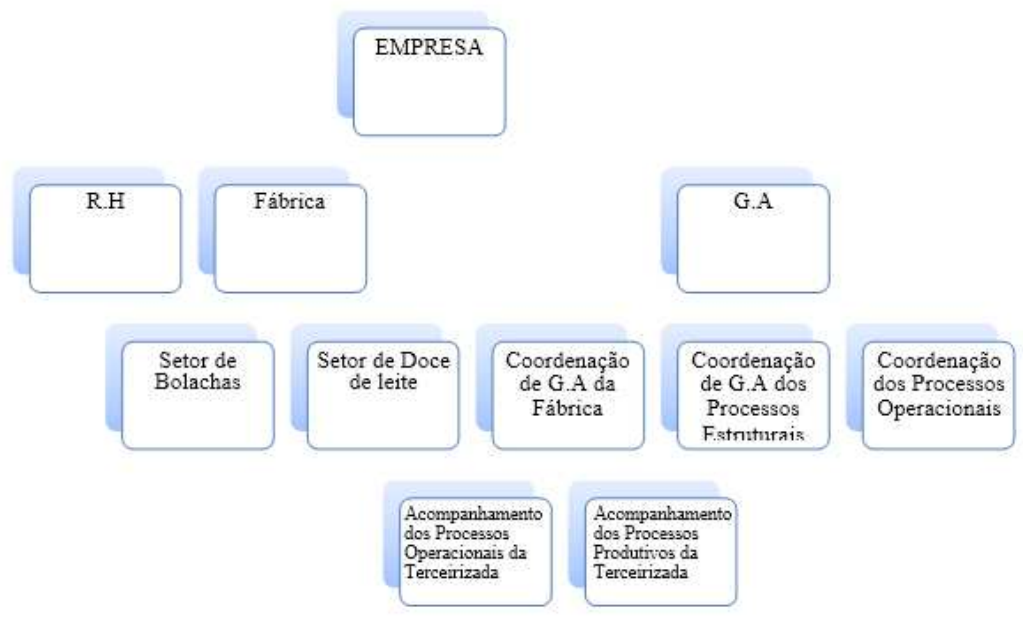

Figura 1 - Organograma de Gestão Ambiental

Segundo Balcão (2011), o organograma é uma espécie de "fotografia" hierárquica da empresa, nele é retratado como se dividem as atividades da organização, assim como foram planejadas pela parte administrativa da empresa. Dessa maneira, o organograma serve para planejamentos dos processos e atividades que ocorrem nas empresas. Este, por sua vez, é responsável pela organização do setor terceirizado de Gestão Ambiental implantado na organização, no qual é possível visualizar a subdivisão do setor de coor- 
denação da área, que passa a acompanhar os processos operacionais, e, ao mesmo tempo, os processos produtivos da terceirizada.

Precisava-se encontrar um meio para guiar, de forma prática e com o olhar organizacional, um modo de definir os processos envolvidos na implementação do departamento de Gestão Ambiental, pois o projeto necessita de planejamento, definições de envolvidos e controle de cada processo realizado. Com o passar das etapas, poder-se-ia analisar melhorias e até refazer algum processo; por esse motivo, utilizamos o fluxograma linear, para mostrar a sequência de trabalho encontrado nesse processo.

O fluxograma é um gráfico universal, que descreve os fluxos e a ordem de qualquer atividade, produto ou documento, pois permite que o funcionamento de um sistema seja verificado e desta forma, localiza se há alguma falha ou deficiência no mesmo, auxiliando assim, na tomada de decisões (CURY, 2010).

De acordo com Slack et al. (1999), é por meio do fluxograma que se tem uma compreensão, em detalhes, das partes do processo onde ocorre algum tipo de fluxo. Para que isso ocorra, deverão ser registrados os estágios da transição das informações, dos produtos e dos trabalhos, de forma a manter uma sequência lógica, em que uma ação será registrada num retângulo e uma questão/decisão será registrada num losango.

Para Moreira (2011), "o fluxograma do processo deve ser representado, graficamente, para demonstrar o que ocorreu com o material, ou conjunto de materiais, durante as fases do processo produtivo". Na referida empresa, foram necessárias a criação e a implementação de um sistema de gestão ambiental, para que, assim, fosse possível uma industrialização mais sustentável e organizada. 


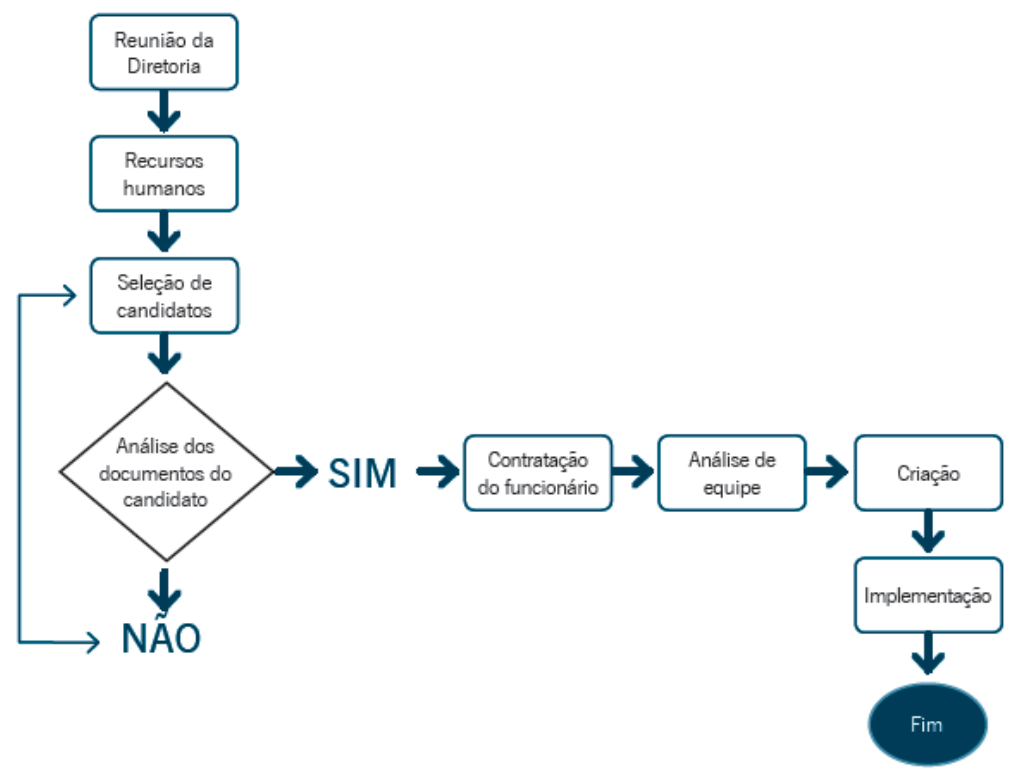

Figura 2 - Fluxograma para Criação do departamento de Gestão Ambiental

O fluxograma nada mais é que uma forma gráfica que se utiliza de símbolos para descrever e mapear todas as etapas de um processo, de maneira lógica e bem planejada (RODRIGUES, 2006). A figura 2 foi utilizada para definir o passo a passo dos processos realizados, desde o momento da decisão, no nível gerencial, até a definição da equipe e a implementação do departamento.

\section{Método PDCA}

Segundo as ideias de Daychouw (2007, p.131), "o PDCA é aplicado principalmente nas normas de sistemas de gestão e deve 
ser utilizado em qualquer organização de forma a garantir o sucesso nos negócios independente da área ou departamento".

Neste estudo, o Plano de Melhorias Contínuas foi utilizado para a implantação da Norma ISO 14001:2004 na empresa em questão e foi desdobrado de uma maneira bem prática para a organização, na forma de metas.

Procurou-se abordar de que forma ocorreriam os processos de contratação, treinamento, verificação e, finalmente, a ação a ser desenvolvida pela empresa. O ciclo começa pelo planejamento, e, em seguida, as ações passam pela execução; checa-se o que foi feito, através de um controle, e toma-se uma ação para eliminar os defeitos, ou até mesmo para decidir a melhor maneira de se executar a atividade:

a) PDCA de contratação - Objetivou a valorização dos colaboradores que com conhecimento na norma ISO 9001 já contratados pela empresa, para que trabalhassem em conjunto com os novos contratados:

- Planejamento: Prestigiar os colaboradores já contratados pela empresa que possuem conhecimento sobre a ISO 9001 e realizar novas contratações de pessoas capacitadas para desempenhar o trabalho de desenvolvimento da ISO14001;

- Execução: Realizar seleções para analisar o perfil de cada candidato que se candidatar à vaga de contratação;

- Controle: Através de critérios estabelecidos, avaliar-se-á como o candidato se comporta perante determinadas situações na empresa; 
- Ação: Através de trabalhos desenvolvidos em equipe e em testes baseados em questionários, avaliar-se-á se o candidato será contratado ou não para a vaga.

b) PDCA de treinamento - Procurou-se realizar treinamentos necessários para qualificar as pessoas envolvidas no desenvolvimento da ISO 14001, para, assim, alcançar o objetivo com mais facilidade:

- Planejamento: Através de treinamentos, procurar qualificar os colaboradores para desempenhar de melhor forma sua função;

- Execução: Desenvolver técnicas para manter os colaboradores sempre informados sobre a ISO 14001;

- Controle: Com a análise de resultados e o auxílio de planiIhas, será feito um controle, para ser constatado se as metas estabelecidas estão sendo reais e alcançadas;

- Ação: Através de palestras e disponibilização de material explicativo, os colaboradores terão como obter maior conhecimento sobre o trabalho a desenvolver.

c) PDCA de verificação - Procurou-se fazer uma avaliação do desempenho da equipe através de planilhas:

- Planejamento: Avaliar se o resultado da equipe foi satisfatório ou não;

- Execução: Fazer planilhas de cada período avaliado, para que, assim, possam ser feitas comparações em cada avaliação seguinte; 
- Controle: Fiscalizar o desempenho e o trabalho em equipe, e se esses estão atendendo às exigências estabelecidas;

- Ação: Realizar observações dos documentos em períodos de curto prazo para ter um acompanhamento real sobre o desempenho.

d) PDCA de ação - Utilizou-se para avaliar os resultados finais:

- Planejamento: Analisar se os resultados estão sendo positivos ou negativos;

- Execução: Fazer observações dos resultados, identificar o que está satisfatório e o que não está sendo realizado de forma correta;

- Controle: Administrar o empenho e o comprometimento de cada colaborador para o cumprimento das metas;

- Ação: Realizar reuniões para debate do que está sendo realizado e o que pode ser melhorado, para melhor desempenho da atividade.

\section{Conclusão}

O estudo proporcionou uma análise do cenário atual de uma empresa e das suas estruturas organizacionais. A partir desse contexto, foram criados alguns Métodos e Sistemas para melhorar a organização, em favor da implementação de um departamento de gestão ambiental em uma unidade de produção terceirizada.

Dessa forma, a atividade contribuiu para o desenvolvimento de habilidades e competências do profissional em administração, que tem como essência a formação teórica e prática, voltada à viabilidade e sustentabilidade das organizações. 
Acredita-se que o desenvolvimento de atividades como a apresentada, que possibilitem ações formativas, proporcionando significado e aprofundamento ao conhecimento acadêmico, mediante a contextualização e a interdisciplinaridade, são significativas para o processo de aprendizagem e são premissas que o Curso de Bacharelado em Administração do Instituto Federal Farroupilha Campus Santa Rosa/RS observa na formação de seus acadêmicos.

Por fim, entende-se que a sala de aula deve, sim, proporcionar atividades que conduzam o aluno para situações aproximadas da realidade, para que, de maneira concreta, empreendedora e criativa, ele seja capacitado para as adversidades inerentes a sua atuação profissional e ao mundo do trabalho.

\section{Referências}

ALBUQUERQUE, Daniela. ISO 14001 e a Legislação Ambiental Brasileira. São Paulo: [s.n.], 2011. Disponível em:

$<$ http://certificacaoiso.com.br/iso-14001-legislacao-ambientalbrasileira/>. Acesso em: 19 out. 2015.

BALCÃO, Yolanda F. Organograma: representação gráfica da estrutura. Revista HSM Management, n. 87, 2011.

BRASIL. Lei no 11.892, de 29 de dezembro de 2008. Institui a Rede Federal de Educação Profissional, Científica e Tecnológica, cria os Institutos Federais de Educação, Ciência e Tecnologia, e dá outras providências. Disponível em:

<http://www.planalto.gov.br/ccivil_03/_ato2007-

2010/2008/lei/l11892.htm>. Acesso em: 15 maio 2015.

CONSELHO NACIONAL DE EDUCAÇÃO. Resolução CNE/CES no 4 de 13 de julho de 2005. Institui as Diretrizes Curriculares Nacionais do Curso de Graduação em Administração. Disponível em: $<\mathrm{http}: / /$ portal.mec.gov.br/cne/arquivos/pdf/rces004_05.pdf>. Acesso em: 15 mai. 2015. 
CRUZ, Tadeu. Sistemas, Organização \& Métodos. São Paulo: Atlas, 2002.

CURY, Antônio. Organização e métodos: uma visão holística. 8. ed. São Paulo: Atlas, 2010.

DAYCHOUW, Merhi. 40 Ferramentas e Técnicas de Gerenciamento. 3.ed. São Paulo: Brasport, 2007.

DIAS, Reinaldo. Gestão Ambiental: Responsabilidade Social e Sustentabilidade. 2. ed. São Paulo: Atlas, 2011.

FERREIRA, Luiz F. et al. Contabilidade Ambiental Sistêmica. In: CONGRESSO UFSC DE CONTROLADORIA E FINANÇAS E INICIAÇÃO CIENTÍFICA EM CONTABILIDADE, 2, 2008, Florianópolis. Anais... Florianópolis: [s.n.], 2008.

HÖFLER, Claudio E. et al. Gestão de Resíduos e Efluentes. Curitiba: Livro Técnico, 2014.

HÖFLER, Claudio; JUCHEN, Dionise; WAGNER, Adriano. Gestão e Negócios: estratégias, processos e ferramentas para o desenvolvimento organizacional. Santa Rosa: Instituto Federal Farroupilha, 2014.

INSTITUTO FEDERAL FARROUPILHA. Plano de Desenvolvimento Institucional 2014-2018. Santa Maria: IFFaroupilha, 2014. Disponível em:

<http://www.iffarroupilha.edu.br/site/midias/arquivos/2014816145120 955pdi_2014_2018.pdf> Acesso em: 14 maio 2015.

MAGRO, Luciana; TELÓ, Admir Roque. As mudanças organizacionais em Fusões e Incorporações. [S.I : s.n.], 2011.

MOREIRA, Daniel Augusto. Administração da produção e operações. 2. ed. São Paulo: Cengage Learning, 2011. 
NETO, J. L. et al. A importância do sistema de gestão ambiental (SGA): estudo de caso na empresa grande Rio Honda em Palmas Tocantins. Palmas: [s.n.], 2011.

OLIVEIRA, Rafael Rez. Conheça o 5W2H: uma poderosa ferramenta de gestão. 2014. Disponível em:

$<\mathrm{http}$ ://www.cursomarketing.com.br/marketing/conheca-o-5w2huma-poderosa-ferramenta-de-gestao/> Acesso em: 10 out. 2015.

INSTITUTO FEDERAL FARROUPILHA. Campus Santa Rosa. Projeto pedagógico do curso de administração. [S.I.: s.n.], 2014.

Disponível em:

<http://www.sr.iffarroupilha.edu.br/site/midias/arquivos/20155158563 7447ppc_-_bacharelado_administracao_-

_santa_rosa_oficial(junho2015).pdf>. Acesso em: 10 jun. 2015

ROCHA, Luiz Oswaldo Leal da. Organização e Métodos. São Paulo: Atlas, 1998.

RODRIGUES, Marcos Vinicius. Ações para a Qualidade - GEIQ: Gestão Integrada para a Qualidade - Padrão Seis Sigma - Classe Mundial. 2. ed. Rio de Janeiro: Qualitymark, 2006.

SANTOS, Antônia A.M.; GUIMARÃES, Edna A.; BRITO, Giliard P. Gestão da Qualidade: Conceito, Principio, Método e Ferramentas. Revista Científica INTERMEIO, Fortaleza, 2013.

SLACK, Nigel et al. Administração da produção. São Paulo: Atlas, 1999.

TEIXEIRA, O. A. Interdisciplinaridade: problemas e desafios. Revista Brasileira de Pós-graduação, Brasília, v. 1, n.1, jul. 2004.

VERGARA, Sylvia Constant. Gestão da Qualidade. 3. ed. Rio de Janeiro: FGV, 2006.

VITERBO JUNIOR, Ênio. Sistema Integrado de Gestão Ambiental. 2. ed. São Paulo: Aquariana, 1998. 